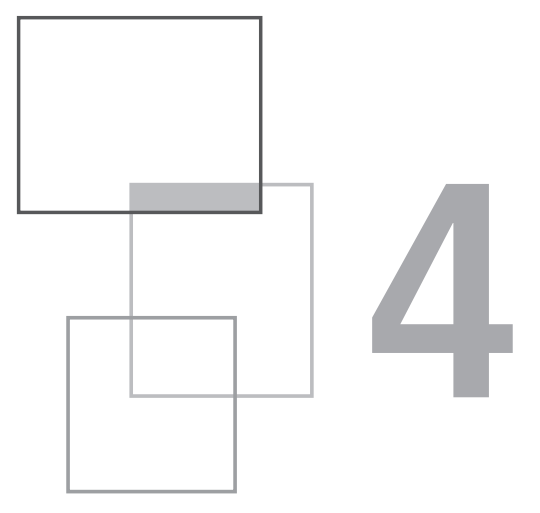

\title{
Administration of informational propulsion
}

The administration of an informational propulsion of Society concerns the activities around its information services and its informational commons. Its task is extremely delicate, since it faces three crucial situations:

- the great heterogeneity $(\$ 2.1)$ of their builders;

- a plethora of potential situations of cognitive confusion among the contributors of many different facets and dimensions of the informational domain $(\$ 2.3 .1)$;

- the concordance of informational propulsions inducing the progression of Society.

This chapter begins by introducing the general framework of the missions of the administration of an informational propulsion. It continues with presenting a protected place adapted to co-construction of information services, called Third Place for Service (TPS). This administration of an informational propulsion is consecutively placed within the framework of an informational policy, which requires the establishment of the Informational Authority. Finally, an institutional instrument of the administration of informational propulsions, called People-Public-Private Partnerships for Services (4PS), is presented. 


\subsection{Mission of the administration of the informational propulsion}

The main mission of the administration of the informational propulsion is to continually maintain the cognitive unity of the informational propulsion among its contributors, despite their heterogeneity, as well as to ensure its cognitive identity within Society, despite its disruptive aspects. It has a valuable asset - the sense of any informational propulsion $(\$ 1.2 .5 .2)$, which is essential to all works regarding co-creation of services and of information common goods.

On the other hand, this mission confronts the threat of a primary thought that defines dominant attitudes $(\$ 1.1 .4 .1)$. Although obsolete, this primary thought remains present and cognitively inviting by its tempting fascination: indeed, it invites actors, who are responsible for informational propulsion and for the progression of Society, to ignore multiple complexities, by engaging themselves instead in fascinating perspectives, which perfectly sweeten a bitter taste of these complexities! Of course, the complexities inevitably arise sooner or later, during different phases of the progression of Society. However, there is an enormous difference for responsible persons, who have now received a real cognitive luxury - not to be considered responsible!

\subsubsection{General framework of the mission}

The administration of the informational propulsion has the mission of writing a declaration aiming to present the intention to overcome situations that could lead to impasses in the progression of Society. This intention is part of the perspectives or challenges of Society. It provides a common reference for all persons involved in propulsion: contributors to information services, persons responsible for the progression of Society, or ordinary citizens. It must enable them to define the sense of the informational propulsion. It must also operate as a ferment of cognitive cohesion.

This intention must be built on basic principles understandable throughout Society, so that Society could adhere to the explorations of informational propulsions that will be conducted and then implemented. However, these informational propulsions deeply question functioning of Society and, consequently, its regime. These basic principles must be at the height of the stakes of these upheavals to maintain cognitive cohesion at the level of the whole Society.

The French Revolution of 1789 found itself faced with a cognitive situation of the same nature, even if its circumstances are totally different from those of informational propulsions. It needed a cognitive framework to maintain a cognitive cohesion of a multitude of propulsive activities in all sectors of Society, to profoundly transform the existing regime and create a new one $(\$ 1)$. Its motto "Liberty, Equality, Fraternity" served as a common cognitive rally to all these propulsions. 
A comparable cognitive framework is needed for informational propulsions to ensure cognitive unity in Society despite disruptions in the functioning of Society and even its regime. Here is the proposed framework. All informational propulsions must be contributory. This means that all information services that comprise it, especially belonging to its information common goods, must be contributory: democratic, responsible and inclusive:

- an information service of the informational propulsion is of a democratic nature: it must be criticisable and revisable, its sense should be accessible to all concerned persons, as well as its informational models, its digital code and its knowledge, in order to allow consistent debates and requests revisions for changes, evolutions or expansions;

- an information service is responsible: it is developed to ensure its resilience to all kinds of changes in its environment, including regulatory ones; it is sustainable and for this purpose designed and developed to ensure its permanence and growth in the form of evolution and even expansion, in all the levels: digital, informational and activity ones; it is reliable and secure; it is efficient and inspire confidence; it admits components dedicated to the cognitive continuity of its actors from the design phases; it puts its contributors in a resilient and sustainable cognitive situation;

- an information service is inclusive, in order to allow all concerned persons to master its sense and all its critical elements, to access to processes of coexploration, to encourage their commitment to eventual processes of revision, evolution or expansion, to smooth its insertion into Society. Notably, its initial cognitive disruption must be converted into cognitive continuity $(\$ 1.2 .5 .5)$.

It is the responsibility of the administration of informational propulsion to guarantee that the informational propulsion is contributory.

\subsubsection{Different missions}

The administration of the informational propulsion fulfils the following missions: Regarding Society:

- to fight the primary approach with its "solutions", which divides Society into two parts. From one side, these are the digital inventors and their advocates. From the other side, they are the actors whom it considers as mere "users" within Society. This refers to fighting its confinement tendencies that guarantee the inventors a certain luxury not to need to worry about "users", by reducing the role of actors as simple digital consumers or simple guards of all kinds of robots ${ }^{7}$, or by even simply excluding them;

- to fight cognitive exclusion $(\$ 1.2 .5 .3)$;

7. As for example cashiers, surgeons, captains of boats, planes, cars. 
- to ensure the legitimacy of the informational propulsion regarding Society, particularly in terms of law, regulations, standards.

Regarding actors:

- to ensure that all actors, at any level of Society, can continue to be aware of the progression of Society thanks to the direction of the informational propulsion, from persons having the highest level of responsibility to "people below";

- to manage processes of informational innovations, either societal or digital, by guaranteeing actors maximum cognitive serenity, especially by encouraging the implementation of cognitive continuity processes, even in apparent situations of cognitive disruption.

Regarding builders:

- to welcome and manage persons who construct information services by taking into account their heterogeneity; to lead them to reach the corresponding informational level so that they could clearly identify their agreements and disagreements;

- to fight all tendencies preventing from reaching this informational level, especially the tendencies of the primary thought;

- to detect talents.

Regarding the informational propulsion:

- to lead the process of co-construction of information services, ensuring that their sense is clarified and the basic principles - democratic, responsible, inclusive - are respected;

- to organise information common goods into informational commons;

- to watch digital and societal pushes and contra-pushes $(\$ 1.2)$.

\subsection{Place of Propulsion}

Information common goods are the foundations of the informational propulsion of Society $(\$ 3.1)$. They are formed of information services related to multiple institutions, professions, responsibilities, disciplines. It is thus essential to find and encourage people who are creators of tomorrow of Society, who can imagine, conceive, implement them, in a word - build them, by mixing various aspects of engineering and exact sciences with aspects of law, management, human sciences, and by continually conducting explorations.

These people will need a protected place, outside of their own institutions, where they can face their differences, sometimes even their divergences, by focusing on research of the informational consensus $(\$ 2.5)$. A possible candidate for such a protected place is the Third Place for Service. 


\subsubsection{Third Place for Service: concept}

The first Third Place allowing heterogeneous people $(\$ 2.1)$ to undertake innovative approaches that are part of the progression of the Region opened in Saint-Étienne in 2010. It was described notably in (Burret, 2015). A lot of such other places have been further created. Conceptually, such a Third Place is "a social configuration where the encounter between individual entities intentionally engages in the conception of common representations" (Burret, 2017).

This social configuration is an open place that allows co-creation processes involving heterogeneous people. It is sufficient to adapt it to the characteristics of informational propulsions and information common goods, in order to make it the place of their construction under the name of Third Place for Service (TPS): the TPS configuration is a social configuration between different entities whose encounter intentionally engages them in the conception of common informational representations, expressed by means of informational models, in order to construct information services assembling in an information common good.

\subsubsection{Third Place for Service: intention}

TPS initiators propose an action corresponding to an informational propulsion of Society. It is multi-disciplinary, multi-institutional, or multi-national. It is described by a pursued intention, with the sense, which it gives to the subsequent progression of Society. It also describes situations to overcome and societal issues of the informational propulsion.

The main generic activities of TPS are to:

- launch an action within the framework of an informational propulsion of Society: this action is of trans-disciplinary, trans-institutional, or even transnational nature;

- promote the creation of a network of heterogenous contributors, who are eager to get involved into processes of exploration of these situations and to contribute to overcome the corresponding issues, by co-constructing information services thanks to digital platforms;

- allow explorations whose results are actionable, because they are expressed thanks to information services, eventually complex, with their value proposition. It is from these results that the action of the TPS takes the form of exploration of the informational propulsion of Society $(\$ 1.2)$;

- continually explain the sense of the informational propulsion induced by information services under construction;

- maintain the action within the framework of the original intention and the basic informational principles: democratic, responsible, inclusive. 


\subsubsection{Third Place for Service: value}

The TPS generic intention is to place heterogeneous contributors in an environment beyond their disciplines, institutions or nations to carry out explorations to make discoveries that are realised by means of information trans-services $(\$ 2.1)$. This is how they contribute to the progression of Society, as well as to their own disciplines and institutions.

TPS provides them with a framework for all their activities in TPS: the cross-pollination space $(\$ 2.5)$. Despite their heterogeneity, they therefore have a common language, the language of the cross-pollination space, which is the language of the Information World $(\$ 2.5 .3)$. They can understand each other. They know how to benefit from discoveries, in order to conceive informational models essential for the implementation of information trans-services. They even know how to criticise and refine them. They know how to lead to the necessary informational consensus ( $\$$ 3.3.2) between different perspectives to avoid the failure of exploration. Then they invest themselves into explorations of multidisciplinary, multi-institutional or multinational spaces by emerging the points of view that are not usual in their own activities, throughout the process of establishing informational models. They can even lead to the evolution of the TPS intention during such discoveries.

These information trans-services bring the generic value of TPS to the progression of Society. They form the foundation for information common goods and informational commons implemented in TPS.

\subsubsection{Third Place for Service: contributory properties}

In a generic way, TPS is a social configuration that allows all contributors to have access to informational models of the information service. They can therefore criticise these models. They can make proposals for modifications or even progressions. They can give them the sense in the context of the progression of Society.

However, these possibilities are wider if TPS activities follow the informational approach. In this case, all these informational models form the informational base ( $\$ 1.2 .1)$ of the information service. The informational base is the place of steering of all the informational infrastructure of the information service. Thus contributors, depending on their roles in TPS, have access to steering of the information service in all phases of its life cycle, including creation, design, digital and organisational implementation, insertion in various activities, exploitation, evolution.

In this way, TPS provides a framework conducive to the construction of contributory - democratic, responsible and inclusive - information services. 


\subsubsection{Third Place for Service: organisation}

TPS sessions can take many forms, such as face-to-face or virtual meetings, or a combination of these forms. They are all facilitated by a digital platform dedicated to TPS.

In all these sessions, there are many innovative ideas that come up and are exploited. There is no time to slow down or even simply stifle the innovation process with intellectual property issues. TPS takes place under a free license adapted to the constitution of information services and information common goods, following the example of software projects governed by free licenses like the GNU-GPL ${ }^{8}$.

Thus, all TPS contributors must sign an identical agreement, which provides a clear ethical basis for their interactions, as well as offers a free license for information services. According to this convention, during the sessions, they engage themselves to have behaviors adapted to the collective processes of exploration and co-creation; they must be involved, share expertise, knowledge and discoveries resulting from explorations, avoid obstructing the emergence of innovations and new ideas, to ensure other contributors could discover and learn from them listening to their presentations and propositions.

In order to ensure smooth TPS functioning in co-construction of services, in particular to guarantee balanced discussions and efficient decision-making, TPS recognizes the following roles of contributors (Ralyté and Léonard, 2020):

- initiators: they propose TPS with its intention, its situations and its stakes. They invite contributors to propose exploration processes and take initiatives in the context of TPS. After discussions with other contributors, the initiators are the ones who make the final decisions throughout TPS;

- builders: they participate in processes of co-construction of information services, information common goods or informational commons;

- developers: they develop a service both at the digital and organisational levels. They must act within the defined framework for the creation of information services, in particular allowing their evolution and their interoperability with other information services;

- regulators: they ensure the conformity of the envisaged information services with the elements of their regulatory space $(\$ 1.2 .1)$;

- moderators: they take care of the process of TPS functioning, in other words, "neutral" actors who guide discussions towards the concretisation of initiatives; moderators have good skills in informational modelling;

- observers: they attend the discussions but do not actively participate in them. Observers may pursue goals of gaining experience or knowledge (e.g. students, researchers, teachers, etc.) or simply share the general interest of the intention of TPS, without wanting to participate in explorations;

8. https://en.wikipedia.org/wiki/GNU_General_Public_License. 
- historians: they play a supporting role. Thus, they ensure that the sense of cocreated services and the TPS intention continue to become more and more explicit, more deepened, more refined; they record the continual improvements of services and the salient elements of discussions and contributions, they introduce essential information, especially of the regulatory level, to the process of services co-construction, they keep being attentive and respectful to the agreed planning;

- concierges ${ }^{9}$ : they manage the reception and animation processes of TPS. They connect the contributors and let them share skills, knowledge, experience and talents.

\subsubsection{Third Place for Service: conclusion}

Given the multifaceted perspectives of the informational propulsion of Society and its multiple stakes, TPS characteristics make it a privileged place to conduct the informational propulsion in terms of construction of contributory information services.

TPS are prosperous places to create democratic, responsible and inclusive information common goods or informational commons, since they allow gathering conditions indispensable for their construction: to open up skills, to concentrate efforts in order to overcome complex situations, by bringing together institutions, including teaching and academic research, private and public enterprises, government institutions, NGOs, etc.

The TPS motto inspired by Kant (1784) is a place encouraging: Reason, explore, design as much as you like and on the subjects that you like but ensure the informational sustainability!

\subsection{Informational Policy and Informational Authority}

The State plays a special role in the informational propulsion as a guarantor of the general interest in the public spaces of Society. In fact, thanks to information services, an informational propulsion brings out numerous informational public spaces conducive to exchanges and activities that take forms, which were previously unknown. So this continual expansion of the public space leads to redefining the role of the State as a guarantor of the general interest, while preserving the fundamental democratic principles that govern it. At the same time, the particularities of the informational expansion of the public space are also taken into account. The object of this paragraph is to introduce their basic principles.

9. http://movilab.org/ notably from Johann Duriaux. 
Throughout this paragraph, the term Society describes a democratic society whose citizens follow an implicit charter of this type: they do not tolerate arbitrariness, they accept the authority recognised as legitimate by law for well-defined areas and exercised by people chosen by procedures; they respect decisions regarding the organisation of Society and societal practices, as long as they have been debated and amended correspondingly. Finally, to reflect the democratic context of Society, only democratic, responsible and inclusive information services are considered.

The first part of this paragraph presents the role of the State based on the characteristics of the informational propulsion. It establishes a general framework of the informational policy by observing the progression of Society from a quantum point of view enabling it to take into account the effects of information services, whilst the traditional point of view, called gravitational, does not allow it.

The second part concerns the conduct of the informational policy. It determines the responsibilities to be assumed in the quantum space of informational propulsions to guarantee the general interest in the public space. It highlights the importance of an Informational Authority.

\subsubsection{Informational policy}

An informational policy of Society is at the centre of the issues of its progression. Firstly, the informational propulsion is a decisive asset to overcome these issues. Secondly, some issues originate from the potentialities of informational propulsions themselves, of creation of values, activities, jobs, and from formations to observe the Society with the informational point of view. Thirdly, some issues are related to the continual digital pushes that Society can assimilate for its progression in a consistent way only by integrating them into informational propulsions.

An informational policy concerns the implementations of informational propulsions and the expansions of the public space that they induce. It takes care to preserve social progressions in terms of liberty, equality and fraternity, and to respect the previous implicit charter followed by all the actors of Society. It strives to maintain a cognitive serenity in its expanded public space and to fight against the cognitive exclusion of people, enterprises, communities and even Society itself.

An informational policy considers not only of the profound transformations of societal practices, but also of their consequences on functioning of Society itself. It can not ignore the usual tendencies to carry out these transformations in perilous forms: for example, a revolution with the lax illusion to sweep clean all the existing ones to build a completely new Society, or, on the contrary, to bury them by abdicating in front of the difficulties and by imposing the illusion of so-called good old time without digital.

It is about introducing the foundations of the informational policy that transforms without revolution and without abdication, and supports the development of 
multitudes of information services and information common goods, by guaranteeing the general interest in the expanded public space.

This is how the informational propulsion becomes a chance for Society.

\subsubsection{About Society}

By taking into consideration the depth of transformations induced by informational propulsions, it is important to start by questioning the very notion of Society with all its attributes: State, government, fundamental missions, such as education, justice and law, health and medicine, police and army.

Such questioning may seem unreasonable. Yet, there are visions where activities such as justice, banking, notary, medical diagnosis, medical operation, police, army, even government, are controlled by supra-intelligences, with the help of qualified intelligent machines. In this way, citizens are led to accept the authority of the actions and decisions of these supra-intelligences not because they are right but because they are true at the level of the world: and everyone knows that truth is beyond everything! Thus, there is no longer a need for the State, the nations become obsolete, wars can no longer exist, and all people have enough of goods to nourish themselves, to clothe themselves, to heal themselves, to take shelter at good temperatures, to amuse themselves in the freedom provided by cognitive ghettos!

Such visions impose their future, they colonise it. Their propagation in Society is facilitated by the reduction of an informational policy to a simple digital policy, which is centred on technologies and their usages in Society. Such an attitude induces the conditioning of minds to accept, for example, that intelligence could be artificial, that no one is responsible for the cognitive puzzles produced by informatisation, that the only responsible one is the system.

Such visions are absolutely revolting for anyone who is enamoured of humanity. Of course, we can oppose a whole set of knowledge amassed over the course of Humanity. Of course, one can unmask their intellectual embezzlement by noting that these supra-intelligences are designed, directed and maintained by people who will obviously never be in cognitive ghettos. It is possible that these visionaries do not believe in their own visions, but simply seek to take advantage of the credulity of those who listen to them. However, all these oppositions, even being right, become outmoded, outdated, and even archaic under the pressure of the cognitive scroll of these visions.

Why? Because all these oppositions leave aside a crucial and essential element of the progression of Society and the digital pushes. The digital pushes are those that feed these visions. And everyone knows the importance: oppositions act in the way as if these digital pushes are only a detail related to the fundamentals of Society. However, many people do not find in these oppositions any explanation of the events they experience in many different ways, such as cognitive exhaustion, insecurities, stress, creative employment, improvements in their living conditions. 
It is time to put in place the informational policy of Society, in order to capture the chance offered by informational propulsions and to stifle these apocalyptic visions to prevent them from sealing this chance from Society.

\subsubsection{An informational policy to seize the chance of informational propulsions}

To meet the issues of the progression of Society with the help of informational propulsions, it is important to note that it is impossible to simply decree how to meet them, how to bring lasting solutions for anyone of us: leaders, MPs, researchers, experts, etc. It is a question of exploring how to capture wealth that up to now has been unattainable or even unknown, by means of informational propulsions. This exploration requires knowledge of several disciplines, cooperation between several companies or institutions. This exploration requires thinking about tomorrow. Tomorrow is not just the future. Tomorrow is the time of service design; it prepares activities for the future that will be carried out through the provided services. The future is to be discovered, it will be what people will do with these information services all around the world.

In order to capture these potentialities, the informational policy hosts exploration activities, aiming to prepare tomorrow of Society. These exploration activities constitute the quantum space of Society, with its requirements, its rigour, its own knowledge which distinguishes them from the usual activities of Society, constituting its gravitational space.

These two terms refer to quantum physics and gravitational physics. Physics has expanded with the discovery of quantum physics, but gravitational knowledge is still useful: a person sitting under an apple tree is still likely to receive an apple on their head! It is the same at the level of Society: it is expanded by the quantum activities, whilst gravitational activities are still essential.

\subsubsection{Position of the State in relation to informational propulsions}

The administration of quantum activities takes other forms than the administration of gravitational activities. This difference in administration between these activities comes from their different characteristics.

In the gravitational space, the time is the present, the gravitational activities mainly ensure the functioning of Society. Some of them can lead to incremental innovations that improve the efficiency of activities. Others can be implemented in frameworks of projects organised in the gravitational mode with objectives to be reached and returns on investment to be achieved. If they exceed the budgets, if they fail to meet the objectives and to obtain the expected returns on investment, if eventually they are abandoned, then probably they should have been considered from the start in the quantum space. In the gravitational space, even the projects are in present: the objectives, as well as the returns on investment, will be achieved, the deadlines will be respected, and potential hazards will be considered. Even if the project must 
end in a year, the strategic level seems to have the impression to know what will happen, it expects no surprises (no doubt, any surprise will be unwelcome), it has already assimilated in present this project as a successful one.

On the other hand, the time in the quantum space is the tomorrow: Future Perfect and not Future Indefinite. Its exploratory activities are focused on building sustainable eco-systems of activities around information services under construction. The exploration space is multi-disciplinary, multi-institutional, even multi-national, enabling to build information trans-services that will be trans-disciplinary, transinstitutional, trans-national $(\$ 2.1)$. The potential of the quantum space is to take into account fields of exploration of Society that are invisible or even considered impossible from the gravitational viewpoint.

The domain of the quantum space is the domain of cognitive disruption to ensure tomorrow. It is the domain of the gravitational space and the cognitive continuity to secure the present. Both have their raison d'être and both are essential: the quality of their concordance defines the consistency of the progression of Society.

\subsubsection{Informational policy and quantum space}

The quantum space where tomorrow of informational propulsions, and consequently tomorrow of a large part of the progression of Society, are decided, gives space to talents and skills to co-construct their information services. As such, it becomes necessary for both quantum and gravitational spaces of Society to set up new forms of skills, training, jobs and responsibilities, rewards, solidarities, regulations, partnerships, justice, etc. In a democratic Society, the State, as a guarantor of the general interest in the public space, has the responsibility to conduct their constitution. In particular, it is up to the State to extend the rule of law to take into account generic conflict-generating situations in this expanded public space. It is the State and the only the State that has the legitimacy.

As the result, the quantum space of informational propulsions allows the responsible persons of the State not only to be able to anticipate the events these propulsions induce in Society, but above all to be immersed in their co-construction processes and thus to be in the heart of explorations, in order to be ready to defend the general interest and citizens in the expanded public space in the best possible way. On the other hand, the gravitational space, alone, leads the responsible persons of the State to always have to react to events without any hindsight, by enabling the policy centred on the digital and its usages.

The informational policy must be established in the quantum space.

In this way, it can take care of the concordance of quantum and gravitational activities. It focuses on facilitating the enrichment of activities, responsibilities and gravitational missions through information services in the quantum space. It ensures the transformation of the quantum cognitive disruption into the gravitational cognitive continuity, so that gravitational activities continue to be efficient through the information services available to them. 
The informational policy requires in-depth understandings of the domains of Society coming from quantum approaches. They not only re-analyse these domains, in a way which is unthinkable with gravitational approaches, but also make concrete suggestions through information services.

For example, the initiatives of the progression of Society, which are placed in the quantum space, give rise to an informational propulsion whose contributory information services allow responsible activities carrying social and economic values. This makes such initiatives of progression consistent and responsible. Reaching such a level requires that these processes of co-construction of information services are conducted by heterogenous persons $(\$ 2.1)$. As the result, progression initiatives are no longer limited to predefined circles of persons.

Informational policy focuses on facilitating the enrichment of activities, responsibilities and gravitational missions arising from quantum repercussions.

However, it is important that it is accompanied by an institutional framework allowing officials to stay in touch with quantum-based explorations and to be kept informed of their discoveries, as well as the subsequent debates in the decision-making processes of service design. Thus, they can participate in efforts to transform the explored cognitive disruption, conceptually investigated in the quantum space, into the necessary cognitive continuity at the gravitational level, in order to ensure the continuity of activities of Society.

TPS provide a particularly suitable place to explore and implement all the quantum activities of creation and construction of informational propulsions but also, more broadly, of informational policies.

It is now important to present such institutional framework aiming to conduct the informational policy.

\subsubsection{Conduct of an informational policy}

The conduct of an informational policy is entrusted to an Informational Authority, whose mission is to guarantee, in the name of the State, the general interest in the expanded public space and to oversee the progression of Society through information services and information common goods.

The Informational Authority is not of the advisory nature, but of the decisionmaking type, because it engages the responsibility of the State. It is responsible for the informational heritage of Society. Its institutional concretisation is specific to each State and depends on the culture of its Society. It may be is spread out into the executive, legislative and judicial powers, as in the case of the Judicial Authority. Although spread out, it has intrinsic properties to fulfil its role in any informational propulsion, as well as to exercise its responsibilities.

To fulfill its mission, the Informational Authority must be at the heart of all informational propulsions and, therefore, focus on their information common goods and their organisation in informational commons. This is the reason that leads the 
Informational Authority to be a stakeholder in informational commons. However, its responsibilities, its role in the informational propulsion and the scope of its mission should be clarified. These are the topics of the next paragraphs.

\subsubsection{Responsibilities of the Informational Authority}

Informational commons are the nerve centres of any informational propulsion. Since the Informational Authority is at the heart of their activities, it is able to take its responsibilities.

In fact, it is in the informational commons that design decisions regarding the information services of information common goods are made. With access to it, the Information Authority takes into consideration the issues of the informational propulsion in the progression of Society, and ensures the general interest in the expanded public space. So it can take full responsibility to legitimise or not this informational propulsion and to launch the necessary adjustments in various State institutions, out of the informational commons, to keep them in tune with the ongoing informational propulsion.

On the other hand, informational commons are bases on which the ecosystems of enterprises and institutions that create services contributing to the progression of Society and the expansion of its public space are developed. The Informational Authority is thus at the center of the entanglement of the activities of construction and development of information common goods, and of the activities of service creation. The former are carried out within the framework of the economy of contribution, the latter are within the scope of the market economy. The Informational Authority is present at the emergence of new activities and new markets induced by the informational propulsion. It must ensure that they comply with the rules in force of Society.

It is the Informational Authority that validates the conformity of any informational common, especially its institutional form, whether public or private or mixed, so that the general interest is preserved, in particular regarding the access to information and free competition, so that the progression of Society is not hindered. It takes steps to promote the sustainable and consistent integration of the informational common into Society: to maintain, enrich and evolve it as long as it is developing.

The Informational Authority therefore enables the State not only to anticipate the effects of the informational propulsion, but above all to be a stakeholder in its design and implementation. The Informational Authority thus prevents the State from always being in a position to notice the effects of the informational propulsion on Society and to be obliged to react to the effects that seem prejudicial to the general interest. These reactions require a lot of investments in budget and time of competent persons to untangle the complications, solve cognitive crises, find solutions to restrain these damaging effects, without any guarantee to succeed.

The Informational Authority prevents Society from desperate and futile conflict situations that emerge in the case of a gravitational approach. Such situations leave 
the possibility for information common goods, which belong to the expanded public space, to become the property of private interests. Thus, there is a risk that they limit their developments to their own interests and do not take into account other interests related to the progression of Society. They then grant themselves with this already mentioned supra intelligence with all the already mentioned excesses.

The progression of Society may be considerably weakened as it is based on these information common goods. A State would then be dispossessed of them. If it could open its eyes to the prejudice suffered by the general interest, it would face a very difficult task to recover its legitimacy on these information common goods.

\subsubsection{Role of the Informational Authority in the informational propulsion}

Being a stakeholder in the informational propulsion, particularly on the level of design of information common goods, the Informational Authority becomes aware of the inconsistency of certain laws or regulations, which are enacted when there was no informational propulsion. Some of these laws or regulations might be blocking developments without anyone understanding why; the others are lacking rigour in the situations, which are generated by informational propulsions; others, quite simply, are not able to face situations unthinkable by the legislators of the time and coming from the creators of the Digital, for whom everything, which is not explicitly prohibited by law, is legal.

The Informational Authority, which has the mission to facilitate the progression through information services, is thus responsible for the legislative information process, in order to advance the legal framework and ensure legal and legislative responsiveness. It must implement it with the various concerned powers - executive, legislative, judicial - and have it recognised as a democratic process. This requires it to be clearly identified and instituted.

This process is subject to time pressure.

This time pressure does not come from the Authority. It is intrinsic to the processes of co-creation. To understand it, one must remember the important role played by the legislative and regulatory frameworks for the co-construction of information services $(\$ 2.2)$. Any uncertainty related to them de-stabilises a team of contributors in full co-creation, as one should wait for the uncertainty to be removed without knowing the delay. This situation may lead to stops in the co-creation process: it will then be very difficult to restart the work afterwards, to reconstitute the team or to form another team, since talented people who are not so numerous as one might think.

Of course, there are losses of time, money, budget. But, there is another critical situation: a propulsion is stopped and, consequently, ongoing activities will not be finalised. Certainly, at the level of the State, there are many other situations that are much more critical in other areas. 
But, this situation is critical for the Informational Authority. As a matter of fact, the Informational Authority faces risks to lose the trust of contributors who work on informational propulsions. In addition, their ability to facilitate the progression of Society through services is likely to be weakened not only within contributors but also within political circles of the State. It is the entire progression of Society that can suffer unfortunate consequences, including the loss of activities and, therefore, jobs.

Therefore, the Informational Authority must assume their responsibilities facing this time pressure and trigger the legislative informational process, by taking into account not only this time pressure, but also the necessary delays in reflections of the legislative power for amending an existing law and/or for creating a new law.

In a gravitational approach, such interventions with the executive, legislative and judicial branches will most often be interpreted as a form of pressure coming from certain interests. Consequently, either they will not be undertaken, or they will only have very random results.

On the other hand, in the quantum approach, the Informational Authority, as representative of the State, is legitimate to exercise these interventions to guarantee the respect of the general interest in the informational expansion of the public space and to allow the progression of Society.

\subsubsection{Scope of the mission of the Informational Authority}

Although the Informational Authority is a stakeholder in processes of construction of information common goods in the heart of informational propulsions, it has no other power over these processes than to legitimise them by considering only the general interest in the expanded public space. It ensures that information services, either they are under construction or have already been implemented, are contributory. Their contents are under the responsibility of their creators. Creators must be allowed to express themselves in terms of information services and conduct exploratory processes following the informational approach. In this quantum space, the Informational Authority should always keep an eye on the progress without exercising any control over finalised or ongoing works.

It participates in all TPS organised for the construction of information services only with the role of regulator $(\$ 4.2 .5)$.

If the Informational Authority had the power to master the construction process, it would fall back into the throes of the gravitational approach: it would need to establish master plans and apply them through top-down or bottom-up methods, in correspondence to the objectives, which should be achieved. In this case, however, it will be virtually impossible to escape disciplinary or institutional traps, to achieve a contributory progression of Society. And above all, it will be almost impossible to face the issues of Society that come in multi-disciplinary, multi-institutional and even multi-national forms, as, for example, the issue of an habitable Region or 
projects of Smart(er) City when they are reduced to the digital predominance inside the design process.

\subsubsection{Informational Policy: conclusion}

Facing multiple issues of the progression of Society and their trans-disciplinary, trans-institutional, trans-sectoral, trans-professional, even trans-national characteristics, the State must fulfil its role of being responsible for the public space, which is considerably expanded by informational propulsions. It needs an institutional tool, which would help, on one hand, to consistently allow and support the contributions to the multitude of innovations and constructions of information services, and on the other hand, to empower the Informational Authority who would guarantee its citizens that all these information services in this public space are contributory. This institutional instrument should enable the progression of Society, which is induced by informational propulsions formed around contributory information services. This is the subject of the next paragraph.

\subsection{Institutional instrument of informational propulsions: 4PS}

It is necessary to have an institutional instrument for elaborating and conducting an information policy of Society as and when it is progressively driven by informational propulsions. This instrument is designed in the way that all contributors for propulsions can operate efficiently and fully fulfil their responsibilities. In particular, it allows the Informational Authority to fully exercise their responsibilities. It is also designed in the way to allow reticular processes of exploration and construction.

Given the multiplicity of activities and responsibilities concerned by any informational propulsion, this instrument makes it possible to form the necessary partnerships between all physical and legal persons, the world of private or public enterprises, public administrations, associations, national or international organisations, research and training centres interested in contributing to the co-construction of one or another information service of an informational propulsion. It is called the People-Public-Private Partnership for Services (4PS).

It is essential to constitute the generic framework of 4PS and to define their raison d'être, expressed in terms of intention, confronted crucial situations and stakes for Society. Then it is a matter of considering their implementation in Society by proposing accompanying measures in Society to facilitate their growth in the progression of Society. 


\subsubsection{Framework of 4PS}

The generic framework of 4PS is based on the informational approach (\$ 1.2). 4PS proposes to explore a domain of Society by means of information services. All information services of $4 \mathrm{PS}$ are contributory, i.e. democratic, responsible and inclusive (\$ 4.1.1).

\subsubsection{Raison d'être of 4PS}

The raison d'être of 4PS is to enable a progression of Society in this domain through information services, which can not be considered without information services.

Its raison d'être provides the context to determine the overall intention of the informational propulsions to be explored inside 4PS with the help of contributory information services.

Its raison d'être must show its importance in the progression of Society by describing the overall situations to overcome.

Its raison d'être provides its relevance by highlighting the overall issues to the progression of Society in terms of values. They concern their feasibility in terms of democracy, responsibility and inclusion. They concern the risks to be circumscribed, the first of them of not undertaking $4 \mathrm{PS}$.

\subsubsection{Actions of 4PS}

The activities of 4PS are divided into several 4PS actions, which themselves have their own domain and their own raison d'être - intention, situation, issues - that must conform with the ones of 4PS.

The activities of an action of 4PS aim at constructing information services intended to constitute the endogenous services of common goods of information. The contributors work in the contributory framework of Third Place for Service (TPS). All this work is done using informational models ( $\$ 1.2 .1)$. These models are the basis of all debates around cross-pollination spaces $(\$ 2.5)$ and all decisions relating to the construction of information services, in all their stages, such as exploration, design, implementation.

\subsubsection{Informational commons}

For each information common good, each 4PS action must constitute the informational common, which organises all the activities around it. Several information common goods can be organised by the same informational common.

Thus, each 4PS action must develop management rules specific to its domain, as a part of the generic proposals for the organisation of informational commons described above ( $\$$ 3.3.2). These rules concern the endogenous services of information common goods built as a part of the economy of contribution, and the 
exogenous services developed within the framework of the market economy. They must also concern the sustainability of the information common goods, which serve as a basis for exogenous services, and thus concern their supply of new endogenous services or information, their administration, their maintenance, their evolution, their budget and their institutional position in Society. All these rules are dependent on the related sectors of activity, as well as the culture of Society.

\subsubsection{Informational overlap}

The informational space $(\$ 2.2)$ of an information common good is formed by the union of the informational spaces of the endogenous services that compose it.

The constitution of an information common good is independent of the composition of another common good of the same 4PS action, as long as they are managed to ensure their informational overlap $(\$ 2.5)$, i.e. the common parts of their informational spaces.

In the same way, two actions of the same 4PS are independent as long as their informational overlap is managed jointly, in other words, the common parts of their informational spaces formed respectively by the union of informational spaces of their information common goods.

\subsubsection{Exploration and construction}

4PS is focused on tomorrow of Society. Its intention is to generate one or more informational propulsions to contribute to the progression of Society. The character of $4 \mathrm{PS}$ comes from the very nature of its exploration and construction activities.

An exploratory activity can not be locked into a project; it is of a quantum nature $(\$ 4.3)$, whereas a project is of a gravitational nature. The project world requires management composed of investments, objectives to be achieved, solutions to be found using digital systems, deadlines to be respected, budgets not to be exceeded, start and end dates, returns on investment, inspections of finished work. The world of 4PS is turning away from this world of project which it uses only in circumstances circumscribed in budget, deadlines, objectives to be reached, etc. The world of 4PS is built around explorers, creators of activity spaces using information services, cognitive passers between the worlds of quantum cognitive disruption and the worlds of gravitational cognitive continuity $(\$ 2.2 .5 .5)$.

Not knowing the basics of the construction of information common goods limits the possibilities of creation and construction of exogenous services. This construction is highly dependent on the digital systems which are being used. And they conform to societal contra-pushes (\$2.2.3).

The contributors of 4PS can not invest in it only in a perspective of return on investment. They are in another dimension. They commit to tomorrow of their own activities. They contribute to the creation of information common goods of 4PS and then enter the market emerged by 4PS to create exogenous services of these 
information common goods from the endogenous services. Without 4PS, there is no market. Without contributing to it from the very beginning, there is a crucial risk of not being able to enter the market, in particular because of the lack of knowhow with the endogenous services.

Every contributor to 4PS knows that other contributors to 4PS share the same spirit.

\subsubsection{Legitimacy}

4PS induces informational propulsions that lead to the expansion of the public space. It is the Informational Authority ( $\$$ 4.3.2.1) that has the responsibility to legitimise them or not. The Informational Authority has a special place in 4PS: to be in current of all advancements by participating in cross-pollination tables while respecting the scope of its raison d'être. They must make sure they avoid the situations leading to not legitimising an informational propulsion induced by 4PS, by giving warnings to responsible persons regarding the conduct of 4PS activities, by taking into account the legislations, the regulations or the opinions of law.

The Informational Authority must also be a partner of 4PS in the case when current laws or regulations are not adapted, even inapplicable, or simply non-existent for the situations emerged from the informational propulsion, which is induced by 4PS. In this way, it is the responsibility of the legislative informational process to advance the legal framework and ensure legal and legislative responsiveness.

New regulatory or legislative frameworks can be developed. But then, nothing guarantees their sustainability, in regard of the usages of information services. It is the responsibility of service providers to prepare them for these possible changes, especially at the digital level. This is what is required for an information service to obtain the quality of responsibility.

\subsubsection{Domain of 4PS}

The domain of 4PS must have the scale allowing its intention to confront complex - multi-institutional, multi-sectoral, multi-professional, even multi-national - situations of the progression of Society. The underlying issues of the progression of Society must attract enterprises, in the broadest sense: private, public, associative, people working in these enterprises, as well as citizens, because they see their own tomorrow by committing to contribute to 4PS activities, with their know-how, knowledge and talents. This area must be so important to its own tomorrow that some of them find a clear interest in launching an initiative of a 4PS action.

All these people contribute to bringing value to the progression of Society. They can only commit if, from the very beginning of 4PS, its conduct ensures sustainability of the activities generated by 4PS around informational commons, information common goods, endogenous and exogenous services. 
In particular, the Informational Authority must be specifically interested in the 4PS success, because among all the governmental authorities, it is the best placed to understand how much the information common goods of 4PS enrich the public information heritage, ensure the emergence of value-adding activities that could not exist without endogenous and exogenous services, and make a substantial contribution to the progression of Society. It must promote it within all relevant government authorities. It must be particularly attentive to ensuring the resilience of informational commons to transformations in their environment, as - for example - changes of political majority.

\subsubsection{Overall intention of 4PS}

The overall intention of 4PS provides a first framework for the exploration and construction of contributory information services that are pursued. This overall intention is decomposed into several intentions which provide the main thrust of informational propulsions to be explored and triggered as part of the progression of Society.

The raison d'être of 4PS provides the context for the overall intention of 4PS, which provides a first framework for the exploration and construction of information services that will be pursued. This overall intention is decomposed into several intentions which provide the main thrust of informational propulsions to be explored and triggered as part of the progression of Society. All these intentions must be described in such a way that once 4PS actions have begun to build promising future foundations, they can be re-examined, criticised, refined and possibly modified or even transformed, depending on these results. They are at the centre of the cognitive cohesion of all 4PS contributors. They must enable them to find a cognitive unity respecting their differences by allowing them to bring value from their talents and knowledge and to establish informational consensus between them. These intentions must also allow 4PS and, consequently, all its contributors and all activities carried out within it, to have a cognitive identity clearly identified in Society. This cognitive identity will be forged throughout the activities of 4PS, by continually enriching the sense of the constructed information services.

Then these intentions describe the critical situations for the progression of Society, which 4PS intends to face. These situations must be extensive given the wealth and variety of knowledge, experiences, know-how of all 4PS contributors. These situations must be crucial: 4PS activities must allow Society to pass a large-scale cognitive threshold and not only the specialists must be able to overcome it, but also all the concerned people.

Finally, these intentions describe the issues of its activities. These issues make it possible to determine the factors of success. All these issues concern activities around information common goods, as well as their endogenous and exogenous information services. They depend on their relevance to overcome the critical situations faced by $4 \mathrm{PS}$ using the created information services. An important issue concerns 
the institutionalisation of the informational commons of 4PS, in order to make these activities sustainable and make information common goods accessible and sustainable.

In conclusion, these intentions of 4PS do not contain any promise about the future. Nor are they visions of the future. They envision the creation of tomorrow by letting a whole space of activities emerge.

\subsubsection{4PS intentions}

It is essential to explore institutional frameworks at the international level to establish 4PS, considering that not only information services, but also many other domains pursue the same type of intention of progression of Society.

\subsection{Approach of Public-Private Partnerships}

The classical institutional instrument of the State to manage the relations between the private and public sectors is that of the public procurement inserted into a legal framework governing calls for tenders from the public sector, tenders from the private sector, the selection of the retained tender, the establishment of the contract and the contractual relations between the concerned parties. This legal framework tends to guarantee or enforce values such as fairness between parties, as well as probity and sincerity.

Under the leadership of the United Nations with its Economic Commission for Europe (UNECE) ${ }^{10}$ and other international organisations such as the World Bank, the Organisation for Economic Co-operation and Development (OECD), this traditional approach has been renewed by the introduction of a new instrument of public-private relations, known as public-private partnerships (PPPs), to take into account situations for which the previous approaches have not been taken into account. Generally, PPPs consider partnerships over long periods, sometimes decades, and in more complex domains, such as infrastructure and public services, in all kinds of sectors such as roads, railways, bridges, hospitals, schools, cultural or sports facilities, communication infrastructures, national security facilities. Often, several public sectors and several private sectors are simultaneously involved. Facing these new situations, PPPs intend to be more efficient and effective than classical approaches of the public market.

There are three main types of PPPs widespread in many countries of all the continents.

- the first-generation PPP, based on the UK Private Finance Initiative (PFI), adopted in 1992, is intended to improve the quality and efficiency of the use of tax funds for the acquisition of public services;

10. United Nations Economic Commission for Europe (UNECE) http://www.unece.org/info/ ece-homepage.html. 
- the second-generation PPP, based on the concession mechanism introduced in France for more than a century, aims to promote healthy economic and social development in a regional context by developing societal infrastructures and having them financed at least partially by users;

- the third-generation PPP considers the framework of previous PPPs as too narrow, as soon as the intention of the PPP is not limited to optimising the allocation of tax funds (on the efficiency of fiscal fund allocation) and to respect principles and frameworks of operational achievements, but - on the contrary - concerns broad issues of development of Society. UNECE has launched third-generation PPPs known as People-first-Public-Private-Partnerships (PfPPP), with the major intention to place in the centre of activities the needs of the population within the framework of the 17 Sustainable Development Goals (SDGs) proposed in the United Nations Programme for $2030^{11}$, which has already been accepted by the international community.

\subsection{Position of 4PS}

All of these previous instruments, the classical instrument of public markets and first- and second-generation PPPs, require well-defined objectives, precise deliverables, clear criteria for success, risk allocation, and precise budgeting plans, deadlines, required technical qualities. This framework is inappropriate for dealing with the issues of the progression of Society through informational propulsions: it would probably be adequate if these propulsions were conducted with gravitational approaches, but this would be very harmful to informational propulsions, particularly in their essential exploration process.

In fact, the overall intention of 4PS and that of PfPP are very close, although 4PS partnerships are not necessarily concerned by the SDGs.

Then, the institutional basic principles of 4PS and of PfPPP are similar.

\subsection{Generic 4PS intentions}

Since 4PS concerns informational propulsions, the global intention includes particular generic intentions that relate to the different facets of the informational propulsion. Thus, there is the generic intention to:

1. allow emerging activities, markets, responsibilities;

2. accelerate the adoption of technologies, methods, principles in the context of contributory services;

3. interest the private sectors to contribute to 4PS to advance their methods and technologies, to gain experience, skills and know-how in explorations, to be present at the opening of the market constructed by the activities of 4PS, to have a fluid relationship with the State, to have a guarantee of legitimacy;

11. https://sustainabledevelopment.un.org. 
4. engage the public sectors to contribute to 4PS to construct contributory information services and information common goods that are essential for Society;

5. have an instrument of informational commons to govern emerging markets, the administration of information common goods, the economy of activities of contribution and the economy of those operating in emerging markets, the relations between public and private sectors and the State around information common goods;

6. place the Informational Authority in clear situations so that they can exercise their responsibilities with consistency in regards to executive and legislative powers and in regards to 4PS contributors;

7. disseminate cognitive serenity in Society with respect to digital pushes and accompanying visions;

8. provide the sense to the progression of Society induced by 4PS, drive the progression of Society resulting from 4PS in cognitive serenity;

9. prepare Society for the emergence of the informational infrastructure resulting from 4PS.

\subsubsection{Crucial 4PS situations}

The situations that TPS propose to overcome are not only to improve already existing societal practices by means of information services, but to let emerge the activities, observations, exchanges of values, unattainable without information services.

The following crucial situations are generic and responsible persons and contributors of $4 \mathrm{PS}$ must face them.

1. trans-disciplinary situation:

The co-construction of trans-disciplinary services is not known in traditional approaches. It is more demanding than the construction of interdisciplinary processes;

2. quantum situation:

The quantum situation concerns all 4PS activities related to the processes of exploration, construction and progression of information services. It is not taken into account in traditional approaches that are gravitational by nature. It asks not to think in terms of a solution that would be sufficient to achieve from the objectives. On the contrary, it requires a demanding attitude of exploration and construction and to assume the responsibilities;

3. situation of cognitive atony:

People involved in the domain of 4PS, including people with responsibilities, do not feel concerned by the future of construction proposed in 4PS: they are discouraged by the magnitude of the transformations they imagine, induced by 4PS, and often experience a great weariness by all these perspectives, scalded by 
all the broken promises of the digital. This cognitive atony is not only for individuals, it can also exist at the collective level;

4. situation of the cognitive ankylosis of the State:

The situation of cognitive ankylosis of the State is reflected in the domains addressed by 4PS by a lack or an absence of consistent and sustained effort over time. It comes from several factors including lack of budget resources and lack of expertise. But basically, the ankylosis comes from the fact that the State puts itself in the position of overcoming a single critical situation of Society, which should be the subject of 4PS. Even if the responsible persons place orders for services to the private sector to obtain digital solutions in specific settings, they are cognitively ankylosed, since the response to the crucial situation of Society demands answers of a different scale in comparison to those they can imagine or implement alone, as markets emerge from the construction of information common goods and their informational commons. It is the Informational Authority that can combat this cognitive ankylosis by setting up 4PS partnerships and thus prevent the progression of Society from being considerably slowed down and even hindered;

5. situation of famine or greed in the private sector:

In contrast to the previous situation, the private sector alone can seize a crucial situation that should be the subject of 4PS. It provides solutions, which, even relevant, are quickly confronted by their limitations in relation to the magnitude of the situations and can not rely on the legitimacy that could give them the Informational Authority in the framework of 4PS. The private sector faces thus two extreme positions.

The first position, famine, no longer allows it to integrate its customers and partners in its innovations, can not guarantee their legitimacy. It can no longer go forward, it is in famine, it can only survive by delaying its abandonment as long as possible.

The second position, greed, leads it to create its own societal legitimacy by attracting a maximum of users and customers around its products and relying on the importance of the digital $(\$ 1.1 .1 .3)$. In this case, it privatises the information common goods to ensure its economic survival and, as a result, it destroys the possibilities of creating services different from its own ones. It puts its competitors in famine. Driven by its success and its concern to survive, it can only pursue its innovations to finally reach the limits of its societal legitimacy, despite a possible phenomenal audience: it would have to be the master of the country to obtain it by passing the necessary laws.

These two extreme positions, with all the intermediate positions, are very close to those evoked by the tragedy of the commons $(\$ 3.2)$;

6. situation of exploration:

The exploration is an indispensable phase of the informational approach $(\$ 1.2 .6)$. It is an essential element of the quantum space $(\$ 4.3 .1 .4)$. It clashes 
with classical gravitational approaches that assume that there are always specialists who know everything, that it is just enough to put in place solutions, that they already know the problems they have helped to emerge.

\subsubsection{4PS issues at stake}

The 4PS issues at stake concern all the sectors of Society involved by the informational propulsions built inside 4PS. Here are some significant ones.

\subsection{Issue at stake vis-à-vis Society}

$4 \mathrm{PS}$ is not in the domain of research where the essential is to discover new knowledge without worrying about its usage in Society. It is focused on Society itself and its contributors are responsible for their inputs in Society. This social responsibility concerns information services of informational propulsion of 4PS. It is huge, given the societal importance of digital implementations ( $\$ 1.1 .1 .3)$, which are the information services: it is not a simple digital product. It is about activities, relationships between people both in their professional and private domains, enterprises in all their aspects, human lives tossed from one cognitive space to another. This is a dynamic progression where a management error can quickly lead people to no longer understand each other in their activities, to feel obsolete despite their still useful skills, to feel controlled and finally enslaved by increasing level of data at the information level, to feel servile or helpless, or both.

A progression requires a progress. But a progress is always questionable: what a progress is for some people is not always a progress for others. Precisely, democracy has emerged to make decisions and ensure the inevitable progression of Society. The Humanity knows that it works, despite all its weaknesses and even deviations, in countries of several million inhabitants. Responsibility for decisions is assumed globally by the Assembly of Deputies and the executive power.

This democratic aspect is intrinsic to 4PS: all the important decisions regarding the construction of information services are taken by the contributors according to their responsibilities under the supervision of the Informational Authority, that is responsible for the cognitive serenity of the expansion of the public space in preparation. In this case, it is crucial to ensure the access to the design schemas, to the history of the design of services, to the understanding of the choices made to approve them, to discuss them, to modify them or to reject them. One needs to have access to the sense that the contributors wanted to print in the information service. It is this democratic aspect that makes the term of the progression of Society more consistent than the development of Society, where decisions regarding design are in most cases of a centralised nature.

A critical factor of success is the establishment of this democracy in the administration of informational propulsions. Of course, the form it takes in the context of 4PS is not that well known to the legislative power. It needs to be invented, according 
to situations and cultures. It is facilitated by the inclusion of concerned people who are willing to get involved in 4PS, as contributors.

A democratic decision in 4PS is not final because of the continual exploration of the 4PS domain, which brings new possibilities. It can be refined, even challenged. The information services must be able to evolve and the builders have the responsibility to enable these evolutions and to lead them.

Another critical success factor is the establishment of markets and activities around the endogenous and exogenous information services of the information common goods and the creation of values they bring to Society.

\subsection{Issue at stake of the informational exploration in the progression of Society}

The Information World plays a crucial role in decisions concerning informational propulsions, between the World of Society and the Digital World: in particular, it allows meaningful discussions between their specialists $(\$ 1.2 .1)$.

One of the facets of this intermediation role concerns innovations, the foundations of informational propulsions. They no longer emerge from previous visions transformed into objectives to be achieved, as in the case of a gravitational approach. In a quantum approach, they emerge from an informational exploration conducted within the framework of the raison d'être with consequent consultations between all the contributors.

An important issue at stake is that of digital pushes. With a gravitational approach, on one hand, the promoters of a digital push must convince everyone while being able to express themselves only in terms of visions, and, on the other hand, those responsible for an informational propulsion take their decision only according to their conviction. This way of deciding prevents any relevant argument from having its place, even for the promoters of digital pushes who refuse to convince with fantastic visions, but who simply want to show and demonstrate the value brought by their digital innovation. On the other hand, the informational exploration of a quantum approach precisely demonstrates its relevance in the decision-making process. It even makes it possible to enrich it with the emergence of the societal contra-push directed towards this digital offer $(\$ 1.1 .3)$. The final decision of people responsible for informational propulsion is then assumed in conscience and not only by conviction or connivance.

This informational exploration leads to the construction of the sense of informational propulsion $(\$ 1.2 .5 .2)$ and a cognitive context suitable to its assimilation by all those who are concerned by the informational propulsion. It is another issue at stake of this informational exploration, that of accelerating not only the adoption and the diffusion of digital or societal innovations, but especially their insertion in Society. 


\subsection{Issue at stake of cognitive continuity}

The context of cognitive continuity concerns the passage from the disruptive aspects of an information service experienced by its contributors who create previously unknown spaces of activity into a necessary cognitive continuity for the actors who will be exercising their activities through these services. It is necessary to arrange this passage in 4PS. This development requires presenting to the concerned actors, the sense that the contributors have given to the service, as well as the aspects of their activities that have not changed. It must also provide them with benchmarks such as knowing how to evaluate themselves, knowing the evaluation criteria of their activities, knowing how to appreciate the way in which their colleagues carry out their activities, to be able to help each other, etc. It is for this purpose that the information services of $4 \mathrm{PS}$ are contributory. Contributors who will also be relevant actors have an important role to play: to disseminate the sense of the information service and, more broadly, the sense of the informational propulsion, to all their colleagues.

The issues at stake of cognitive continuity in 4PS are that Society is ready for the emergence of markets and activities that result from 4PS, adopts its information services and appropriates the brought opportunities.

Their critical success factor concerns the position of all persons involved in 4PS facing the progression of Society, not only proposed, but also implemented through 4PS.

\subsection{Issues at stake of informational commons}

The issue at stake of informational commons is to avoid the situations of famine and greed described above. An informational common is the link between the economy of contribution, in which the information common goods are built with their endogenous services, and the market economy, in which the exogenous information services of the information common goods are built.

The markets, in which the exogenous services bring economic value, depend on these informational commons. On them also depend the constitution of the informational infrastructure of Society, which provides the framework for innovative companies with all their freedom to undertake the creation of information services to enlarge the markets for the benefit of the progression of Society.

A critical factor in the success of this issue at stake is the interest that 4PS evokes in public and private sectors, which are concerned by the 4PS domain.

\subsubsection{Cognitive frame of 4PS}

The raison d'être of 4PS, its intentions, its crucial situations and its issues at stake, form the cognitive framework of 4PS. As the explorations progress, it is refined, enriched and even reoriented. But at any time of construction of its information common goods, it serves as a breeding ground for determining the sense of each of the information services that create the common goods of 4PS. It is the basis of the 
cognitive unity between all its contributors of 4PS and the cognitive identity of its information common goods with their informational commons vis-à-vis Society.

\subsubsection{PS in Society}

The institutional instrument of People-Public-Private Partnerships for Services (4PS) appears to be indispensable for the implementation of a long-term informational policy. It provides an institutional framework for the administration of informational propulsions, so that they can play their role in the progression of Society. It enables themes that require long-term efforts, such as public security assisted by a set of information services (Drăgoicea et al., 2019). In particular, it enables the Informational Authority to fully exercise their responsibilities of guaranteeing the general interest in the informational expansion of the public space induced by informational propulsions.

Inserted into the informational approach, 4PS allows to construct information common goods composed of contributory information services, i.e. democratic, responsible and inclusive. They make it possible to organise them as informational commons, so that they can sustainably enable the creation of values through exogenous services built from them. These informational commons tend to avoid situations of the tragedy of the commons, such as famine and greed. They govern the interpenetration of economies, on one hand, the economy of contribution encouraging the creation of information common goods with their endogenous services, and on the other hand, the market economy of enabling the creation of the exogenous services of common goods.

The enterprises that create these exogenous services thus bring value to Society and contribute to its progression. All of these enterprises share 4PS common goods and in such a way, they are not isolated, as in the usual case of start-ups. They constitute a swarm of enterprises $(\$ 3.4 .3)$ supported by informational commons. Moreover, 4PS allows them to considerably reduce the uncertainty regarding the acceptance by the State of their societal innovations based on the exogenous services they have created: the Informational Authority provides the social legitimacy of the information common goods by completely comprehending their sense, which consequently makes them and their exogenous services well positioned to be appreciated in the scope of Society.

Finally, all 4PS are built on the inclusion of people concerned by this domain. It contributes to give sense to the progression of Society that it induces on one hand, by its raison d'être to be continually enriched as long as the explorations are being conducted and their discoveries are being found, and on the other hand, by the sense of each of these information services provided by its manufacturers. These senses are conducive to providing benchmarks for all concerned persons and/or persons who are simply interested in understanding the induced progression of Society. 


\subsection{Administration of informational propulsions: conclusion}

Facing the profound transformations engendered by informational propulsions, the classical approach of the world of Society does not have the necessary perspective to integrate the informational propulsions as part of the policies of the progression of Society. It is distraught to estimate what is right and sustainable in these transformations. The visions of utility presented as obvious by the Digital does not help it to develop a consistent position at the level of Society. The classical approach drives Society to undergo digital pushes.

The administration of informational propulsions is clearly different from the gravitational approaches proposed to the leaders of the State or enterprises, which ignore or do not appreciate the importance of the quantum approach. Indeed, these approaches can not avoid the trap of the top-down approach that requires project proposals submitted to experts who give their opinion and, ultimately, often make a final decision. But how can experts evaluate proposals that are intrinsically disruptive, because most of them are not familiar with their new paradigms and challenges? Unless being colleagues of disruptors who are very few in Society! Unless evaluating not proposals but visions! Unless ignoring the effects of disruptions proposed for Society!

The administration of informational propulsions is based on the observation that does not place the experts in a clairvoyant position with a gravitational approach. It is built on this observation and proposes to avoid this trap, which ultimately can only lead to situations of famine and greed. The world of information no longer serves only as a mediator between the world of Society and the Digital. It becomes the important meeting place for the decisions regarding informational infrastructure.

Since the leaders of Society and/or enterprises do not have time to participate in the exploration and design process, it is the Informational Authority that will take the lead to guarantee on behalf of the State and/or enterprises the social legitimacy of information common goods under construction. The initiators of informational propulsions are not part of the Informational Authority. They propose their initiative with its raison d'être expressed in terms of intentions of the progression, crucial situations that they intend to face and issues at stakes for Society with a first plan of explorations to lead. They must conform to the informational approach by constructing information common goods in the economy of contribution, in order to create markets with the help of information services built from information common goods in the market economy. And all these information services must be democratic, responsible and inclusive, so they become essential for the progression of Society. This is how disruptors are invited without dogmatic hindrance to contribute to the progression of Society. They will have societal success, as soon as their value-generating disruption is transformed into a cognitive continuity for the persons who will continue to assume the responsibilities and the tasks through the services that they have helped to construct and make emerge. And it is the 
Informational Authority who has the responsibility of legitimising this cognitive continuity.

This form of the administration of informational propulsions takes into account the quantum world and also the gravitational world. With a very simple rule: what should be administered in the quantum world can not be done in the gravitational world. Quantum disruptions can only be legitimate at the social level, if they lead to cognitive continuities in the necessary gravitational world of Society.

All this administration of informational propulsions avoids great visions; it makes it possible to return to the foundations of the Digital: everything is a construction which takes time but which advances serenely, unless brutalised by visionaries. The initiators of informational propulsions have nothing to promise: they are here simply to present a sustainable way of construction. 
